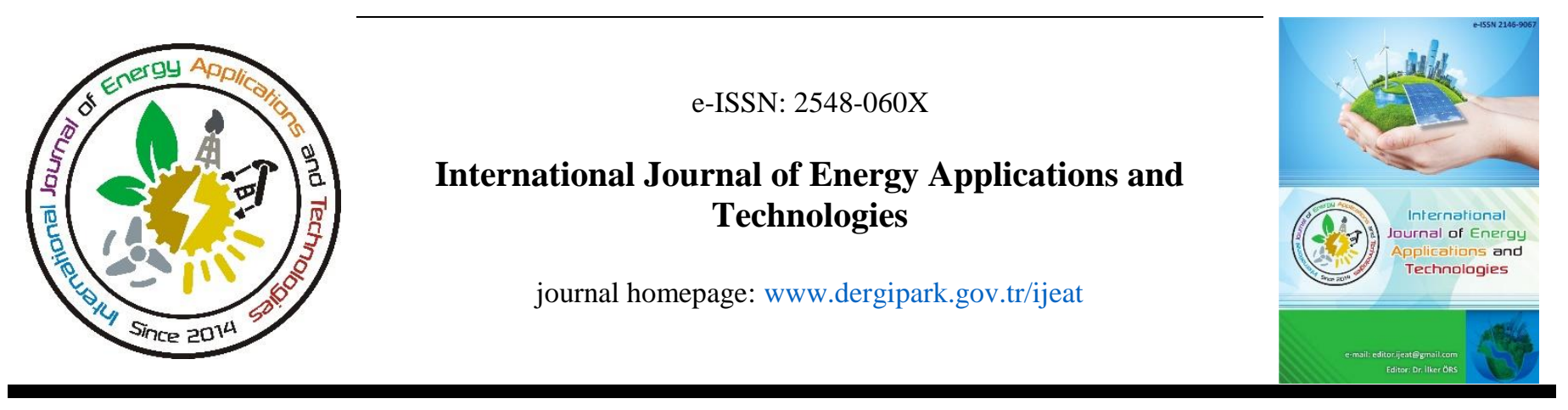

Original Research Article

\title{
Maximum wind speed forecasting using historical data and artificial neural networks modeling
}

\author{
Mehmet Şen*, Muciz Özcan \\ Electrical and Electronics Engineering Department, Faculty of Engineering and Architecture, Necmettin Erbakan University, Konya Turkey
}

\author{
ARTICLE INFO \\ * Corresponding author \\ muh.senmehmet@gmail.com \\ Received September 28, 2020 \\ Accepted December 23, 2020 \\ Published by Editorial Board \\ Members of IJEAT \\ (C) This article is distributed by \\ Turk Journal Park System under \\ the CC 4.0 terms and conditions. \\ doi: 10.31593/ijeat.800937
}

\begin{abstract}
Estimation of the wind speed makes a very important contribution to the seamless integration of wind power plants into the grid. In this way, the maximum amount of electricity can be generated by estimating the amount of energy that can be generated from wind energy. The measurements of the wind speed in the region, where the plant is plant to be established, made before the installation of the wind power plants (WPP), takes between 6 and 18 months. In this study, it was investigated what could be done to make a foresight and estimation about the wind speed in the future for the selected region. In order to accurately determine the wind speed, it was tried to be estimated by using artificial neural networks (ANN) included in the MATLAB package program. In this study, 365 data belonging to the previous years of the region to be studied were provided and used to train the ANN of the planned study. In practice, the parameters of temperature, humidity and pressure, which are among the factors affecting wind speed, were taken into consideration. An $\mathrm{R}$ value of $91.20 \%$ in the training phase, $93.04 \%$ in the validation phase and $92.76 \%$ in the test phase was obtained. High accuracy values were obtained at all phases and it was shown in this study that ANN can estimate reliably without memorizing.
\end{abstract}

Keywords: ANN; Artificial Neural Network; Prediction; Renewable sources; Wind Speed

\section{Introduction}

Energy is undoubtedly one of the most important factors in the development of countries and the reduction of their foreign dependencies. Energy is of great importance in the economic and social development of countries. The demand for electrical energy is constantly increasing due to the rapid developing technology [1-3]. Today, countries meet most of their energy needs from fossils such as coal, oil and natural gas. The share of renewable energy sources is increasing gradually due to the depletion of fossil fuels causing global warming in recent years, their developmental damages [4-5]. Wind energy stands out among the renewable energy sources because it is less costly than other sources [5]. However, the electrical energy obtained from the wind varies depending on wind speed and can lead to production/consumption imbalances in the networks. Both the elimination of these imbalances and the suitability of the region where WPP will be installed in terms of wind speed have an important place in the literature.

The most commonly used methods in the literature in shortterm wind speed estimations are autoregressive, autoregressive floating average and wavelet transform methods. These methods give better results, especially for a few hours [6]. If the estimation periods are extended, error rates increase and these methods cannot yield safe results. Studies conducted outside of ANN show inconsistent results with the increase in data counts. In previous studies, the success rate has not reached $90 \%$. In ANN, the method of achieving high levels of accuracy is to use the most accurate algorithm. [7-8]. For this reason, it is aimed to obtain reliable results in long term estimations by using ANN in this study. The aim of this study is to establish the first stage of network reliability by predicting the maximum wind speed that the 
turbines may be exposed in any win plant depending on the weather conditions. In the study, the region where the wind speed will be estimated has been determined as Ardıçli, Konya and data from previous years has been obtained from MeteoBlue. The average wind speed was estimated by taking the average wind, average temperature, average humidity and average pressure values of the region for 2019. In this way, the maximum wind speed that the region can reach during the day will be determined and the damages that the wind power plants can cause in the network will be prevented. Another advantage of estimating the maximum wind speed is that it allows investors to know this in advance and to trade more comfortably in the intraday and day-ahead market, as wind turbines cannot generate at wind speeds above the operating speed.

\section{Material and Methods}

The data we used for our study was obtained from the MeteoBlue database. The dataset contains variable values for the year 2019 [9]. Some of the data were used for ANN's education purposes and some for testing purposes so that the learning rate of the training was determined. The data was transferred directly to the Matlab program, and the normalization process was not needed because the data did not contain very large numbers. Of the 365 data per year, 256 were used in the training phase, 73 in the verification phase and 36 in the test phase.

\subsection{Artificial neural networks}

Artificial neural networks are a computer system developed in a structure similar to the nervous system in humans. This structure, which is similar to the nervous system, has a network architecture just like the combination of cells and is generally defined as 3 layers [10-11]. The three basic layers are formed by the merging of hidden layers between the input and output layers. A network can have multiple hidden networks. The number of these hidden layers and the number of nerve cells of each hidden layer has not been determined precisely, and solutions are produced by trial and error according to the problem structure [12-13].

When Figure 1 is examined, five basic elements in inputs, weights, net function, activation function and outputs draw attention in artificial neural networks outside of the basic layers. In the input and output layers of the network, there are data to be used to train the artificial neural network. The data in the input layer has certain weights, which directly affect the intelligence and learning performance of the network [13].

Learning method of the network has an important place in ANN. Classical learning methods of the network are divided into two as feed forward and backward propagation. It starts with the presentation of the inputs to the network during the forward calculation phase. Inputs presented to the network come to cells in hidden layer and net inputs are calculated. The hidden inputs are obtained by passing the calculated net inputs through the activation function. The stage of transformation of the artificial neural network making forward calculations into output was expressed in Formula 1.

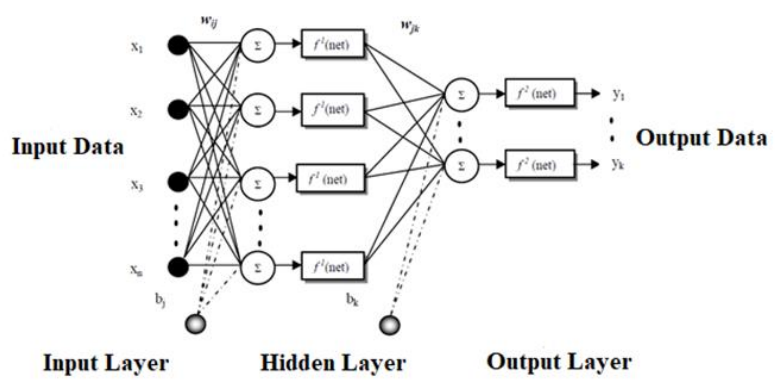

Fig. 1. Architecture of the multilayer artificial neural network [12]

$$
\begin{aligned}
& y_{k}=f_{2}\left\{\sum_{j=1}^{k}\left[f_{1} \sum_{i=1}^{n} x_{i} w_{i j}+b_{j}\right] w_{j k}+b_{k}\right\} \\
& x_{i} \quad: \text { Inputs of the network }(\mathrm{i}=1,2, \ldots, \mathrm{n}) \text {, } \\
& w_{i j} \quad \text { : Weights between the input layer and the hidden layer, } \\
& b_{j} \quad \text { : The threshold (bias) terms between the input layer and the } \\
& \text { hidden layer, } \\
& f_{1} \quad \text { : Activation function between the input layer and the hidden } \\
& \text { layer, } \\
& f_{2} \quad \text { : Activation function between the output layer and hidden } \\
& f_{2} \text { layer, } \\
& j \quad: \text { The index of cells of the hidden layer, } \\
& n \quad: \text { The index of cells of the input layer, } \\
& k \quad: \text { The index of cells of the output layer, } \\
& w_{j k} \quad \text { : Weights between the hidden layer and the output layer, } \\
& \begin{array}{ll}
b_{k} \quad \text { Threshold (bias) between the hidden layer and the output } \\
\text { layer. }
\end{array}
\end{aligned}
$$

In ANN, all data are not used for network learning. After the network training is completed, a certain part of it is used for testing purposes to determine the learning rate. In some cases, while the network gives almost perfect results during the training phase, the network does not perform correct operations by memorizing the network during the test phase. To prevent such situations, the learning rate is determined by providing the network with the values it has never seen during the test phase. In ANN, all data are not used for network learning. After the network training is completed, a certain part of it is used for testing purposes to determine the learning rate. In some cases, while the network gives almost perfect results during the training phase, the network does not perform correct operations by memorizing the network during the test phase. To prevent such situations, the learning rate is determined by providing the network with the values it has never seen during the test phase.

In the backward calculation phase, the outputs are compared with the actual values. The difference between the output results and the actual values is called the error value. Weights 
of the network are changed until the error value is minimum, and re-learning is provided.

In addition to the feedforward back propagation classical algorithms mentioned here, Newton and LevenbergMarquardt (LM) algorithms, which give much faster results, are frequently preferred [15-16]. In this context, the LM algorithm was used for wind speed estimation. In the LM algorithm, the approximate value of a mixed matrix called the Hessian matrix $H(w)$ was taken as a basis. This method was expressed in Formula 2.

$H(w) \cong J^{T}(w) J(w)+\mu I$

$\mu$ : Marquardt parameter,

$T$ : Transposition of the Hessian matrix,

I : Unit matrix.

In the back propagation of the network, the transposition of the Jacobian matrix is taken and the gradient of the network was calculated by making use of the errors in the network. This method was specified in Formula 3.

$\nabla E(w)=J^{T}(w) e(w)$
Formula 4 is used to calculate the change in weights of the network whose gradients are taken. Calculation is performed by multiplying the inverse of the Hessian matrix and the gradient of the network. The process of updating weights of the network was specified in Formula 5.

$$
\begin{aligned}
& \Delta_{w}=-[H(w)]^{-1} \nabla E(w) \\
& w_{\text {new }}=w_{\text {former }}+\Delta w
\end{aligned}
$$

The LM algorithm is an algorithm based on the idea of neighborhood. It is a technique that continues until the local minimum of the nonlinear function is found [17-18]. The LM algorithm, which gives the fastest and most reliable results in feed forward networks, has become a standard technique for nonlinear least squares problems [19-20].

\subsection{Preparation of data for the region of application}

In this study, we tried to estimate the maximum wind speed that may occur during the year with ANN. In this study conducted with ANN, while the daily average wind speed, temperature, pressure and humidity are input data, the maximum wind speed is considered as output data. Some of the data used in the study was given in Table 1.

\begin{tabular}{|c|c|c|c|c|c|}
\hline Day & $\begin{array}{c}\text { Daily Average } \\
\text { Wind Speed (10m) }\end{array}$ & $\begin{array}{l}\text { Daily Average } \\
\text { Temperature }\end{array}$ & $\begin{array}{l}\text { Daily Average } \\
\text { Humidity }\end{array}$ & $\begin{array}{l}\text { Daily Average } \\
\text { Pressure }\end{array}$ & $\begin{array}{c}\text { Daily Maximum } \\
\text { Wind Speed (10m) }\end{array}$ \\
\hline 1 & 3.7 & 4.8 & 85.25 & 1033.57 & 7.91 \\
\hline 2 & 4.0 & 2.2 & 79.17 & 1036.07 & 8.02 \\
\hline 3 & 1.3 & 0.1 & 75.71 & 1038.88 & 4.40 \\
\hline 4 & 2.4 & 1.2 & 79.50 & 1038.18 & 8.30 \\
\hline 5 & 7.9 & 1.9 & 85.25 & 1033.55 & 11.72 \\
\hline 6 & 5.0 & 3.0 & 82.08 & 1032.93 & 8.52 \\
\hline 7 & 2.2 & 2.8 & 80.75 & 1033.59 & 6.11 \\
\hline 8 & 9.6 & 4.3 & 82.08 & 1022.75 & 14.70 \\
\hline 9 & 8.6 & 2.6 & 76.75 & 1016.70 & 12.32 \\
\hline 10 & 6.5 & 0.4 & 82.88 & 1022.93 & 9.71 \\
\hline . & . & . & . & . & . \\
\hline . & . & . & . & . & . \\
\hline . & . & . & . & . & . \\
\hline 364 & 1.4 & 3.5 & 53.79 & 1034.50 & 5.08 \\
\hline 365 & 1.5 & 5.2 & 69.50 & 1032.70 & 4.31 \\
\hline
\end{tabular}

Table 1. Data used in the study

Some of the data was used for training purposes of ANN and some of it was used for testing purposes, so the learning rate of training was determined. The data was transferred directly to the Matlab program, since the data does not contain very large numbers, no normalization process is required. The maximum wind speed used as output data was used to verify the results after training of ANN, so the success rate of the study was determined. The region of application used in the study is located in the north of Konya province. The location of the region was given in Figure 2.

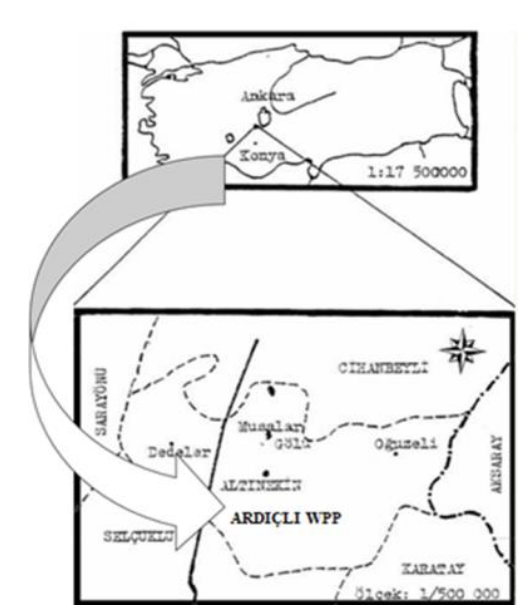

Fig. 2. Location of the region of application used in the study [21] 


\section{Results and Discussion}

In the study conducted, the determination of the most suitable ANN model has been found by trial and error, and the hidden layer parameters have been changed many times. A formula has not been developed in determining the best hidden layer parameters in ANN, but it can be found by trial and error [2223]. A model that provides faster and more reliable results was determined both in the training phase of the ANN and in the testing phase. Levenberg-Marquardt algorithm, which is superior to other models and an advanced version of the feedback propagation algorithm, was used. Many algorithms have been tried to train the dataset, but the highest success rate has been reached by using "traiblm" as training algorithm, learngdm as learning algorithm, tangent sigmoid (tansig) function as activation function and an ANN model has been designed and obtained.

ANN stopping limit in training was determined as a high value of 1000 iterations, but ANN completed training early and stopped before reaching 1000 iterations. Accordingly, 1e-10 gradient value and 1000 verification values were given to the system. The training was completed by reaching 1000 iterations in 13 seconds. Data entered into the ANN interface realized in Matlab program was shown in Figure 3.

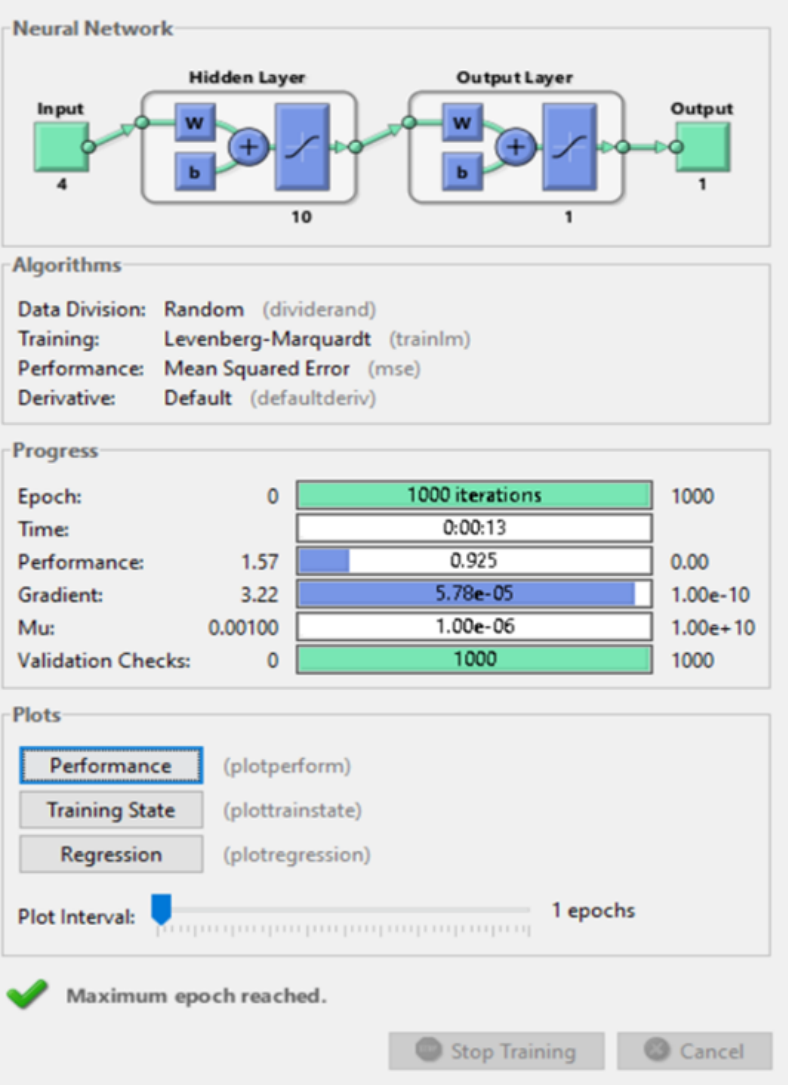

Fig. 3. Matlab YSA interface [21]

After the ANN model was created to estimate the maximum wind speed, training and testing stages were carried out. It was aimed to reach the lowest error value to make an accurate estimate. In this context, the data used in the training phase were not used in the re-test phase, the values were given to the network and the actual learning rate was determined. It was determined that the lowest error value in the training stage of the network occurred at 33rd iteration. Error rates depending on the number of iterations were given in Figure 4.

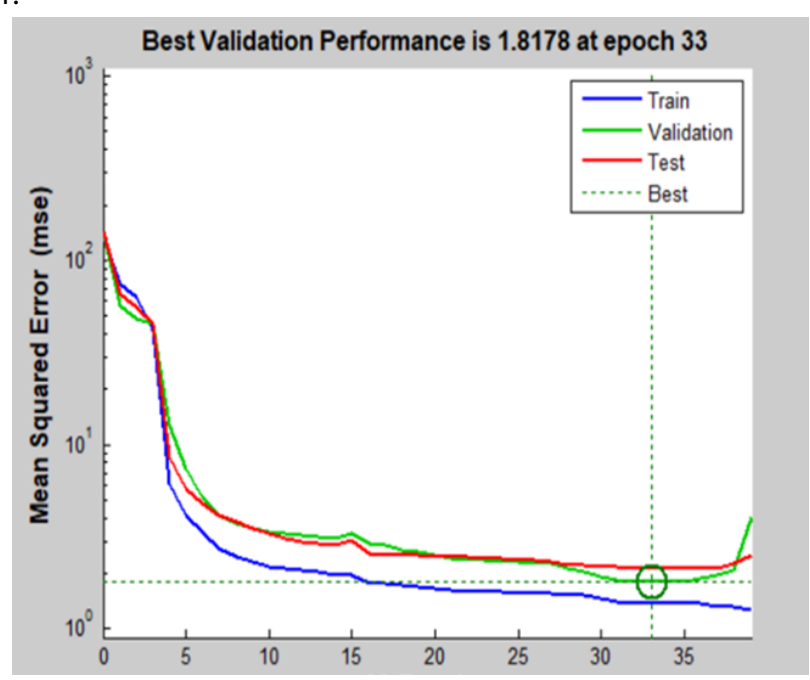

Fig. 4. Changes of the performance function in the training stage of training, verification and test data [21]

As a result of comparing the output values of the ANN, whose training and testing stages were completed, with the real values, the estimated percentage of the system can be calculated. In the study, the regression curves of all data regarding the training, verification and testing stages were shown in Figure 5.

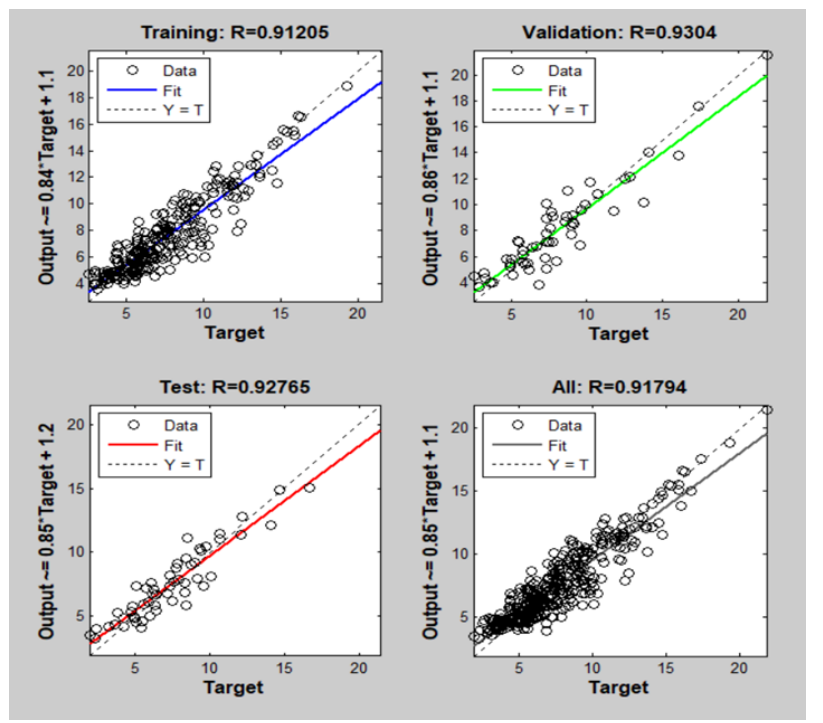

Fig. 5. Regression curves of the results of all data during the training, verification and testing stages [21]

The fact that the regression value approaches to 1 means that the model estimates values very close to the real values. When the test, verification and training stages were analyzed, 
it was seen that the $\mathrm{R}$ value was close to each other and above $90 \%$, giving successful results.

\section{Conclusions}

Wind speed may cause short circuit malfunction as a result of excessive increase on certain days of the year and damage to the turbine and the electrical elements in its equipment. The fact that the braking system in wind turbines cannot be activated at the maximum wind speed may cause such undesired situations to occur. In this study, it was aimed to determine the maximum wind speed beforehand and whether it is ensured that the turbine is placed in the lock position just before reaching the maximum wind speed as software. Thus, it is possible to prevent the mechanical malfunctions that may occur in the wind power plant that may be caused by the increase in wind speed and the possible electrical failures that may occur in the network as a result. The results obtained for the estimation of wind speed at the output of the ANN algorithm developed as a result of the work done were shown in Figure 6 and it was determined that the number of highspeed windy days that can damage the wind plant within one year will be 14 days. This result shows that the region is a suitable location for the wind power plant.

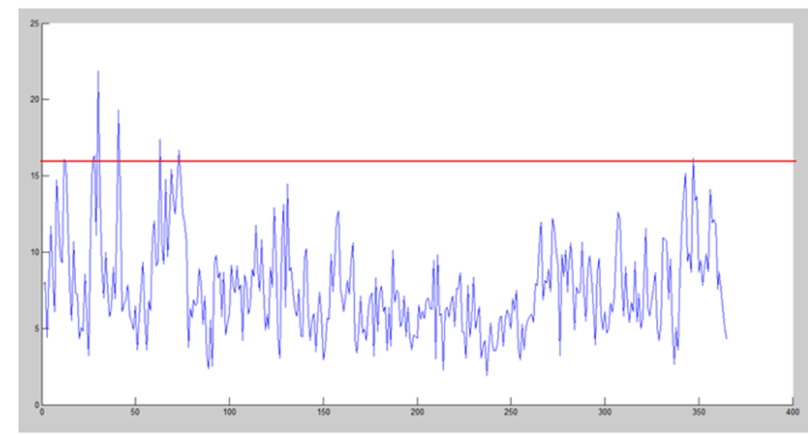

Fig. 6. Maximum daily wind speed obtained at the output of ANN [21]

The annual maximum wind speed in Ardıçlı WPP, Altınekin, Konya was estimated by ANN in Matlab program and an accurate estimation of $91.20 \%$ was made during the training phase. This rate increased to $92.76 \%$ in the test phase, and it was revealed that the learning rate of ANN was very successful. The system was not entered, but it was seen that it can make very correct decisions among the obtained data. In the study, determining the number of layers and choosing the right algorithm enabled the network to produce the fastest results without memorizing. As a result of the obtained work, it can help to predict the feasibility of the investment to be made for the power plant by providing an accurate estimate of the wind speed and by calculating the amount of electricity generation that the power plant can perform for the future. In addition, it was tried to provide a preliminary idea to the institutions or organizations that want to invest in a region based on wind energy on how long the investment they plan to make can be recovered.

\section{ORCID}

M. Şen

M. Özcan

$0000-0001-7609-2210$

$0000-0001-5277-6650$

\section{References}

[1] Wai, R., J., Wang, W., H., Lin, C., Y. 2008. HighPerformance Stand-Alone Photovoltaic Generation System. IEEE Transactions On Industrial Electronics, 55(1),240-250.

[2] Özcan M., Ünlersen M. F., Mutluer M. 2018. Financial Analysis Of The Solar Energy Plant Established In Konya Using The Production Data. 4th Int. Conference on Engineering and Natural Science(ICENS 2018), 2-6 May, Kyiv, Ukranie, 92-92.

[3] Orhan Y., Özcan M. 2019. Turkey's 2023 Target in Electricity Generation. The International AluminiumThemed Engineering and Natural Sciences Conference (IATENS'19), 4-6 October, Seydişehir, Turkey, 259263.

[4] Azad A. K., Rasul M. G., Islam R., and Shishir I. R. 2015. Analysis of Wind Energy Prospect for Power Generation by Three Weibull Distribution Methods. Energy Procedia, 75, 722-727.

[5] Uzun Y., Özcan M. 2020. Rule extraction and performance estimation by using variable neighborhood search for solar power plant in Konya. Turkish Journal of Electrical Engineering and Computer Science, 28(2), 635-645.

[6] Costa, A., Crespo, A., Navarro, J., Lizcano, G., Madsen,H. ve Feitosa, E. 2008. A review on the young history of the wind power short-term prediction. Renewable and Sustainable Energy Reviews, 12(1),1725-1744.

[7] Lei M., Shiyan L., Chuanwen J., Hongling L. ve Yan Z. 2009. A review on the forecasting of wind speed and generated power. Renewable and Sustainable Energy Reviews, 13(4):915-920.

[8] Giebel, G., Landberg, L., Kariniotakis, G. ve Brownsword, R. State-of-the-art on methods and software tools for short-term prediction of wind energy production. Proceedings of European wind energy conference, Madrid, 2003.

[9] T.C. Meteoroloji Genel Müdürlüğü, 2019. https://www.meteoblue.com/tr/hava/historyclimate/we atherarchive/konya_t\%c3\%bcrkiye_306571 .04 June 2020.) 
[10] Skapura, D. M. Building Neural Networks AddisonWesley, New York 1996.

[11] Cigizoglu, H.K., and Kisi, O. 2005. Flow prediction by three back propagation techniques using $\mathrm{k}$-fold partitioning of neural network training data. Nordic Hydrology, 36 (1), 49-64.

[12] Haykin, S. Neural Networks: A Comprehensive Foundation MacMillan. New York 1994.

[13] Öztemel, E., Yapay Sinir Ağları, Papatya Yayıncılık, İstanbul 2003.

[14] Okkan U., Mollamahmutoğlu A., 2010. Yiğitler Çayı Günlük Akımlarının Yapay Sinir Ağları ve Regresyon Analizi ile Modellenmesi, DPÜ Fen Bilimleri Enstitüsü Dergisi 23(1), 33-48.

[15] Kahramanl $\mathrm{H}$ and Allahverdi N. 2009. Rule extraction from trained adaptive neural networks using articial immune systems. Expert Systems with Applications, 36(1), 1513-1522.

[16] Cong Chen T., D. Jian Han, F. T. K. Au, L. G. Than. 2003. Acceleration of Levenberg-Marquardt training of neural networks with variable decay rate. IEEE Trans. on Neural Net., 3(6), 1873-1878.

[17] Marghny H. 2011. Rules extraction from constructively trained neural networks based on genetic algorithms. Journal Neuro Computing, 74(17), 3180-3192.

[18] Minns, A.W. and Hall, M.J. 1996. Artificial neural networks as rainfall runoff models. Hydrological Sciences Journal, 41(3), 399-417.

[19] Sharma R. and Suhag S. 2017. Novel control strategy for hybrid renewable energy-based standalone system. Turkish Journal of Electrical Engineering \& Computer Sciences, 25(3), 2261-2277.

[20] Hsu, K., Gupta, H.V. and Sorooshian, S. 1995. Artificial neural network modelling of the rainfall runoff process. Water Res. Research, 31(1), 2517-2530.

[21] Şen, M. 2020. "Rüzgâr Enerji Santrallerinin Modellenmesi ve Kisa Devre Analizi”. Master. thesis, Necmettin Erbakan University, Institure of Sciences, Konya, Turkey, 31-44.

[22] Raju L, Sakaya M and Mahadevan S. 2017. Implementation of energy management and demand side management ofa solar microgrid using a hybrid platform. Turkish Journal of Electrical Engineering \& Computer Sciences, 25(3), 2219-2231.

[23] Campolo, M., Andreussi, P. and Soldati, A. 1999. River flood forecasting with a neural network model. Water Resources Research, 35(1), 1191-1197. 